\title{
Digital system information model: future-proofing asset information in
}

\section{LNG plants}

1 Peter E. D. Love D.Sc., PhD

Professor, School of Civil and Mechanical Engineering, Curtin

University, Perth, Australia (corresponding author: p.love@curtin.edu.au) (Orcid:0000-0002-3239-1304)

2 Jingyang Zhou PhD

Senior Research Fellow, School of Civil and Mechanical Engineering, Curtin University, Perth, Australia (Orcid:0000-0002-1201-6435)
3 Jane Matthews PhD

Professor, School of Architecture and Building, Deakin University, VIC, Australia (Orcid:0000-0003-3367-9278)

4 Giorgio Locatelli $\mathrm{PhD}$

Professor, School of Civil Engineering, University of Leeds, Leeds, UK (Orcid:0000-0001-9986-2249)
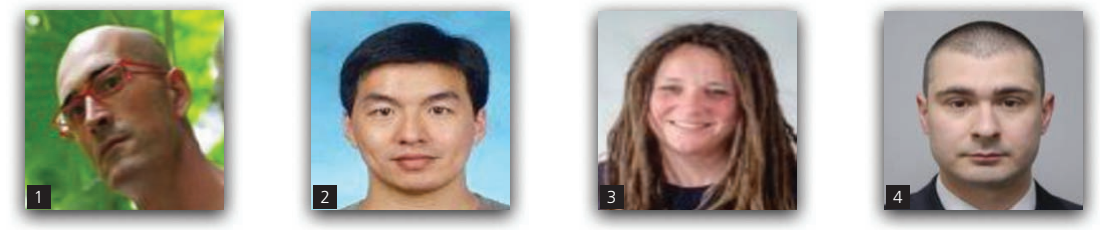

Rework during construction is often required due to errors and omissions contained in the engineering documentation that is produced. If errors and omissions go undetected, they may become embedded within the 'asbuilt' documents that are provided to an asset owner at practical completion. In the specific case of instrumentation and control systems (ICSs), errors and omissions are often found in as-builts. This adversely impacts productivity and safety during the operations and maintenance process, as information is not readily available. In the case of liquefied natural gas (LNG) plants, for example, shutdown periods may have to be extended, which can jeopardise the production and supply of gas and therefore place a strain on energy markets. The research presented in this paper aims to address this issue by proposing a novel digital system information model which can be used to improve the robustness of an LNG operator's asset information management system. The creation of a digital model provides a platform for future-proofing LNG assets and minimising the duration of shutdown periods. The research provides the LNG sector with an innovative solution for digitising their ICSs so that assets can efficiently and effectively be maintained and operated.

\section{Introduction}

As the world looks to diversify its energy mix, natural gas has become an increasingly important source of power, particularly as it is considered a low-carbon dioxide alternative to coal and petroleum. In Australia, for example, natural gas is the third largest energy resource after coal and uranium (Appea, 2017). With an abundance of natural gas available, Australia has become the world's second largest exporter of liquefied natural gas (LNG) behind Qatar, with exports forecasted to be AU\$37 billion (US $\$ 25 \cdot 5$ billion) in 2018-2019 (DISR, 2017). High gas prices in the 2000s prompted a major investment in Australia's LNG industry. For example, in the last 5 years, three onshore LNG plants have been constructed in Western Australia alone to process gas from fields in the North-West Shelf: $(a)$ Pluto, $(b)$ Gorgon and (c) Wheatstone.

The construction of LNG plants in Australia, however, has been the subject of intense criticism by investors, unions and the media, as all have experienced significant cost overruns and contractual disputes (Olaniran, et al., 2017; Smyth, 2017). Rework during construction has been a prominent contributor to cost overruns being experienced in many LNG projects (BCA, 2013; Olaniran et al., 2015). A considerable amount of this rework can be attributed to the production of poor-quality design and engineering documentation that contains errors and omissions (Chambers, 2010; Love et al., 2017). During construction, additional payments are often made to an engineering, procurement, construction and management contractor, as they are required to modify, update and reissue documentation when errors and omissions are identified (Love et al., 2014). Having to revise manually and reissue documentation can result in further errors occurring and the creation of 'as-built' documentation that does not marry with what has been constructed and installed on-site, particularly for instrumentation and control systems (ICSs) (Love et al., 2017). In plant operations, for example, the ICS is critical for ensuring their safety and efficient operation and can account for $60 \%$ of maintainable items (Davis, 2012: p. 38). It is therefore imperative that as-built ICS documentation is error-free and reflects precisely what has been installed.

Relying on as-built documentation for ICSs, which typically contains incorrect and/or missing information, can hamper 
productivity during the planned maintenance of an LNG plant. Having access to quality data during an asset's operation is critical for ensuring that it performs at optimal capacity (Moloney et al., 2017). Extending shutdown periods due to poor-quality asset information can hinder the supply of gas to domestic and international markets. To address this problem and in light of the moratorium that has been placed on the construction of future LNG plants in the short to medium term in Australia, it is proposed that the creation of retrospective digital system information model from existing computer-aided design (Cad) drawings would improve the robustness of an LNG operator's data management and provide a nascent platform for futureproofing its asset information.

This paper starts by identifying the gaps in the existing literature with regard to ICS documentation in the energy sector. A description of the process used to create the ICS documentation for an LNG plant is then presented. Using a case-study approach, the errors and omissions contained within ICS as-built documentation are identified. The potential use of system information modelling (SIM) as an alternative to Cad-based methods is examined, and its cost, benefits and risks identified.

\section{Knowledge gap: ICS documentation in the energy sector}

Instrumentation and control engineers are responsible for designing, developing, installing, managing and maintaining equipment that is used to monitor and control engineering systems, machinery and processes (Parnell, 2013). There are numerous ways to define and document instrumentation and control processes for a processing facility, such as an LNG plant. Most, however, are produced in the form of drawings that are schematic in nature and identify how items are connected, although not how far they are apart from one another. Such drawings do not focus on orthographic dimensions; rather they concentrate on establishing relationships between elements (Meier and Meier, 2011). Traditionally, ICSs have been designed and documented using $\mathrm{Cad}$, even though this medium is more appropriate for mechanical, piping and structural drawings where geometric properties are required.

With the increasing complexity of ICSs, it has become difficult to incorporate and capture the information needed to coordinate and manage their installation in energy assets. Recognising the need to embrace digitisation, LNG operators have begun to embrace the concept of building information modelling (Fakhimi et al., 2017; Mejilænder-Larsen, 2015). The created model acts as a repository of information and is used to facilitate decision-making throughout an asset's life cycle (Pocock et al., 2014). However, such models, or parts thereof, have been restricted only to elements that possess geometric properties and not those of a semantic nature (Love et al., 2017), the corollary being that Cadbased tools are still being used to document ICSs.

Modelling semantic information within an object-oriented environment remains a challenge and is a line of inquiry that remains unresolved. This paper, however, goes some way to address this problem by presenting a platform to enable the modelling of semantic information for ICSs. The research presented in this paper addresses this issue head-on within the LNG sector by identifying problems with existing Cad-based approaches. Similar studies have been undertaken in other industrial sectors, such as the mining (Love et al., 2013, 2016a), rail (Love et al., 2016b) and petrochemical sectors (Love et al., 2019). These industry-specific studies have reinforced the underlying problem that impacts the ability to manage ICS assets effectively and efficiently when they are documented in a Cadbased environment. While the research context presented in this paper is unique, the proposed solution to future-proof asset information is akin to previous studies undertaken by Love et al. (2016b). In the next section of the paper, the traditional Cadbased approach to engineering and documenting ICSs within the energy sector is presented.

\section{Engineering documentation for an LNG plant}

The typical design stages of an LNG plant are presented in Figure 1. The conceptual design is represented as a block-flow diagram (BFD), which is created to simplify and understand the basic structure of the system that has been specified. Once established, a more complex process flow can be designed which represents the general relationships between materials, equipment and facilities. This then leads to the creation of a process-flow diagram (PFD) for the equipment and instrumentation used to control a process.

Often, due to time constraints, the design of piping and instrumentation diagrams (P\&IDs) is carried out prior to the finalisation of PFDs. When this situation arises, there is an increased likelihood for the design to be subject to changes in scope and for errors and omissions in documentation to arise (Love et al., 2014). Revising the P\&IDs can be a time-consuming process and potentially delay a project and result in additional costs being borne by the operator.

P\&IDs illustrate the relationships of the piping, equipment and instrumentation of a plant based on predefined symbols and labels (ISO 14617-1:2005 (ISO, 2005), ISO 10628-2:2012(en) (ISO, 2012)). Specific information such as pipe classes and sizing,

Conceptual design BFD

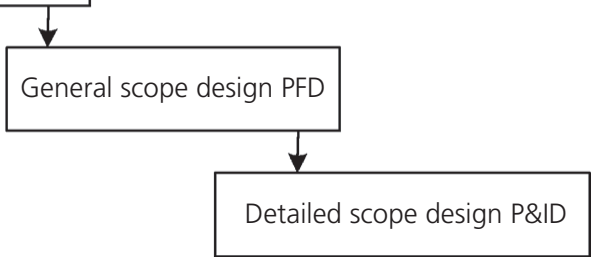

Figure 1. Plant design stages 
material flows, valves, sensors, actuators, control system and other miscellaneous components can be found on a P\&ID. While international standards for symbols and labels to be used on P\&IDs exist, there is nothing in place to describe the level of detail presented. This paucity of standards has resulted in widespread discrepancies between the asset information required by operators and that produced by engineers.

\section{Instrumentation and control system}

The role of the ICS within an LNG plant is to monitor process signals, such as pressure, flow and temperature, and apply control strategies to ensure that the systems can meet the requirements for process and safety control (Love et al., 2017). The type of documents used to create an ICS solution includes instrument list, equipment layout, loop diagram, input/output (I/O) list, causeand-effect (C\&E) diagram, control narrative and software coding (Figure 2) (Meier and Meier, 2011).

The functions of these documents are as follows.

- Instrument list. This is an index of all the devices that are to be installed. It establishes the connections between devices and project documents using tag names and their numbers. The instrument list serves as a 'master', which is used to trace and locate information. Traditionally, engineers manually create the instrument list in a paper format. This is a timeconsuming, costly and error-prone process (Love et al., 2016a). To maintain and update the information contained on a list is a cumbersome and costly task, as a design change may require modifications to multiple drawings.

- Equipment layout. This is used to indicate the location of field instruments and devices within a plant using simple notations, such as tag numbers. The document is created based on the LNG plant's plan.

- Loop diagram. This is created based on the safety function analysis of the LNG plant. A loop diagram describes the structure of a process loop by indicating the interconnections between devices (e.g. sensors, transmitters, indicators, controllers and actuators) which are used to control a process variable. The information presented on a loop diagram should be sufficient for the users to identify the terminations of cables, signals and devices (e.g. cable cores, terminal block numbers). Notably, the ISA-5.4-1991 standard (ISA, 1991: p. 22) indicates that each diagram should depict only one loop and all the devices measure and control a single process variable.

- C\&E diagram. This defines the reactions of the ICS in response to the system states that have been identified. For example, when the liquid level in a tank exceeds a set point and triggers the level alarm, the system response could be 'open the outlet valve to reduce the tank level'. The C\&E diagram is usually presented using a matrix with the 'cause' being placed on the left-hand side and the 'effect' at the top.

- I/O list. This is an index of the instruments that are equipped with I/O functions of a control system. The information shown on an I/O list includes the tag number, I/O type, loop number and P\&ID number. The I/O list can be used to estimate the size of the control system and evaluate the effort that is required for program coding.

- Control narrative. This summarises the functions of the LNG plant by breaking the process into different units and subsystems. The functions of each unit and subsystem and their interactions with others are described. A control narrative should also contain an instrument list, which defines all the alarms and software functions to be used in the system. The control narrative is a critical reference document that is used by programmers to code the control system programs. It is also used as training material for the system operators.

- Software coding. Programmable logic controllers (PLCs) are typically used as a process controller. The control functions are achieved using PLC logic, which is usually coded in a ladder diagram. Thus, this eliminates the need for traditional

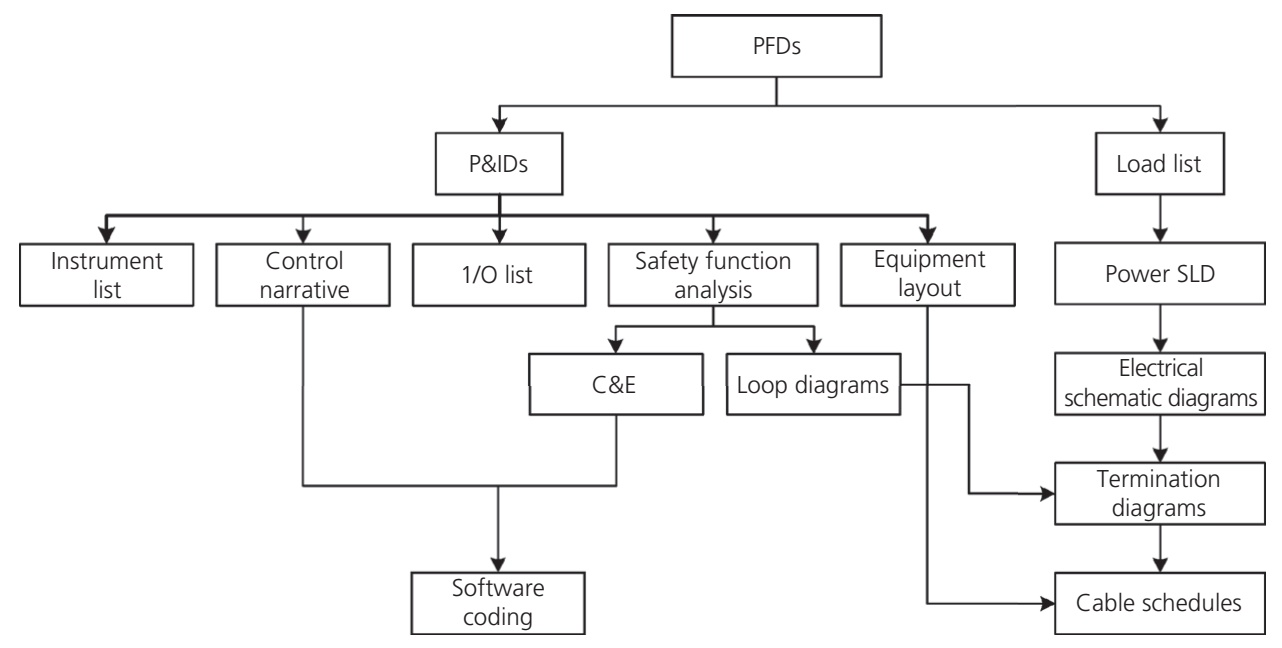

Figure 2. Design and documentation flow for ICS 
relays and timers. The input signals collected from the field sensors are sent to the input terminals of the PLC and processed based on predefined logic and parameters. The obtained output commands will then be delivered to the field actuators through the output portals. It is worth noting that, while the ladder diagram language is widely adopted, PLCs manufactured by different companies can have different naming and coding conventions, which poses difficulties for exchanging information between different systems.

Electrical power must be supplied to the system to energise instruments and devices. Several electrical engineering drawings are also required, which primarily include the following (Figure 2).

- Single-line diagram (SLD). This is a simplified representation of the energy flow for a three-phase system. Instead of showing each phase using a separate cable and terminal, the SLD utilises a single conductor to represent all the three phases, which provides a concise view of the electrical power distribution.

- Schematic diagram. Here the interconnected circuits between components are shown using symbols to illustrate an abstract view of the system structure.

- Termination diagram. This is used to show how each core of a cable is terminated to the target terminal of a device. It sometimes can be represented in a table format listing the cable cores and the corresponding terminals.

v Cable schedule. This is typically represented in a table format, and the details provided include cable number, type, colour, termination devices and grade.

The creation of ICSs and electrical systems for an LNG plant can involve several engineering firms, contractors and subcontractors, each with their own method of working, standards and procedures. Their systems, however, must be compatible and capable of being integrated to ensure an LNG plant's integrity. When a change is required within a Cad environment, each corresponding view has to be updated manually. As drawings are manually coordinated, there is a high risk for documentation errors to materialise, particularly during the engineering of complex ICSs and electrical systems for an LNG plant, which can comprise thousands of drawings (Meier and Meier, 2011).

Empirical research has revealed that, on average, it takes 40 person-hours to produce an individual ICS Cad drawing (Love et al., 2013). Yet, there is a likelihood that omissions, incorrect and inconsistent labelling of devices and wrong connections will be present on the drawings. When such drawings are issued for construction, contractors and subcontractors are confronted with erroneous and incomplete information. The consequences are potentially four-fold: $(a)$ additional costs to the works as a result of scope changes; (b) losses in productivity; (c) rework that not only increases project costs, but can also have an adverse impact of safety; and ( $d$ ) the generation of as-built documentation that is not fit for purpose.

\section{Case study}

With the aim of improving the quality of ICS documentation produced for future LNG plants and existing 'as-builts' used for managing assets, a case study is used to highlight the inherent problems that materialise as a result of using Cad-based approaches. To overcome the problems that are identified, a novel object-oriented engineering platform for preparing ICS documentation, referred to as SIM, is presented.

A case study is a research strategy that aims to engage in a process of empirical inquiry that investigates a phenomenon within its real-life context (Yin, 2014). According to Gerring (2005), it can be used to address specifically questions that focus on explaining 'how' and 'why' phenomena occur. In this instance, the research focuses on how to future-proof the ICS of LNG plants to ensure that the supply of gas is not interrupted and that shutdown times are not increased, as a result of poor information quality contained in the as-built documentation that is produced.

Under the auspices of an illustrative case study, which is descriptive in nature and seeks to make the 'unfamiliar familiar' with a new concept (Stacks, 2013; Yin, 2014), the research starts by empirically quantifying the prevailing issues adversely impacting the creation and management of information of ICS assets. In doing so, the authors provide a justification for 'why' SIM should be adopted, which then provides a springboard to demonstrate 'how' it can be implemented in practice and contribute to improving the performance of LNG plants.

\section{Case selection}

Australia has constructed seven LNG plants. These plants vary in size with the amount of LNG being supplied to international and domestic markets ranging from a production capacity of 3.5-16.3 million tonnes per annum. All have complex ICSs in place, although similar in the nature of their design. An enormous amount of ICS documentation is produced for each development, and access is limited due to issues of confidentiality and security. In collaboration with a contractor, who had been involved with installing ICSs on several LNG plants, it was decided to select a case that had been in operation for a period of time and where issues associated with the as-built documentation had come to the fore as a result of errors, omission and information redundancy. Due to the sheer amount of ICS documentation that was available, it would have been unfeasible to examine the plant in its entirety, so, in this case, the Sulfinol unit was examined, as it forms an integral part of an LNG plant.

\section{Data collection}

The as-built ICS documentation of an LNG plant was provided by an oil and gas company to an electrical instrumentation and control company (company EIC), contracted to upgrade the safety instrument system (SIS). The documents listed in Table 1 are typical of an ICS project, and those denoted with a 0 were not available in this case study, as they had been misplaced by the LNG operator. However, the type of documents made available 
conformed to the IEC 61355-1 standard (IEC, 2008). The documents relating to the Sulfinol unit are examined in this study (Table 1). Unfortunately, an instrument list had been misplaced, which rendered the task of determining what had been actually installed difficult. By examining the available P\&IDs, the number of instruments and devices used in the Sulfinol unit could be manually obtained.

Table 2 lists the major devices and the instruments that were related to the ICS. Notably, equipment that was not connected to the monitoring and control system was excluded. The I/O list and the control narrative were also missing. Without such information, it was difficult to interpret the underlying engineering philosophy of the ICS. With the assistance of several practicing engineers and a series of informal discussions over a 2-month period at the contractor's office where the examination of the documentation took place, the researchers were able to acquire a basic understanding of the ICS philosophy that had been used. Discussions with engineers from company EIC revealed that the as-built documentation provided for the LNG facilities was often incomplete.

\section{Table 1. Documents for the Sulfinol unit}

$\begin{array}{lc}\text { Type } & \text { Number } \\ \text { P\&ID } & 6 \\ \text { Instrument list } & 0 \\ \text { Equipment layout } & 0 \\ \text { Loop diagram } & 121 \\ \text { C\&E } & 1 \\ \text { I/O list } & 0 \\ \text { Control narrative } & 0 \\ \text { PLC software coding } & 1 \\ \text { Alarm schedule } & 1 \\ \text { SLD } & 0 \\ \text { Schematic diagram } & 0 \\ \text { Termination diagram } & 0 \\ \text { Cable schedule } & 0\end{array}$

Table 2. Instruments and devices in the Sulfinol unit of an LNG train

\begin{tabular}{lc} 
Type & Number \\
\hline Control valve & 37 \\
Indicator & 5 \\
Junction box & 21 \\
Motor & 2 \\
Panel & 1 \\
Proximity switch & 5 \\
Push-button & 2 \\
RTD & 23 \\
Hand switch & 3 \\
Transmitter & 53 \\
Heat exchanger & 5 \\
Pump & 8 \\
Column & 2 \\
Vessel & 6
\end{tabular}

RTD, resistance temperature detector

\section{Case background}

Due to issues of commercial confidentiality, the LNG plant in this research is referred to as GASP. It has a number of LNG processing trains, domestic gas trains, condensate stabilisation units, liquefied petroleum gas (LPG) fractionation units and storage and loading facilities for LNG, LPG and condensate. The GASP has been in operation for an extended period of time. Its ageing equipment had become a reliability and safety problem and had the potential to jeopardise the plant's integrity and performance.

The plant's safety systems comprised a process safeguard, fire and gas emergency shutdown and depressurisation. The PLCs that were used to implement the systems had a complex hardware structure and function, which provided many points of potential failure. The diagnostics were deemed poor and often misleading by the GASP. The system had started to show signs of increasing failure rates. A list of recorded failure events for the PLC systems, for example, over an 8-year period are presented in Table 3.

The failures were random events. No projections, with any degree of confidence, can be made about future failure rates other than they will continue to increase with time. Failures of the PLC systems may result in

- false trips (i.e. due to faulty wiring or breaker), which result in loss of production and possible reduction in the life of equipment due to shutdown and start-up stresses

- failure of the safety-related system to operate on demand.

Increasing failure rates can also potentially jeopardise the operation of the plant, which may result in losses in revenue (i.e. reduction in the supply of gas) and endanger the lives of those operating the facility. To maintain effective and efficient operations and ensure the production of LNG at the plant, company EIC were required to

- replace the PLCs and fire and gas panels in field control rooms

- install two fibre-optic loops

replace the catalytic gas detectors connected to field control rooms.

\section{Analysis of as-built documentation}

When the engineering documentation was created for the Sulfinol unit, equipment information was often presented on multiple Cad drawings and documents. To ensure that the equipment can be readily identified, it is vital that each item is clearly and consistently denoted across all documents. In the case of the ICS, this should be undertaken using a standard naming convention for all items that are tagged. Examination of the documentation provided for the Sulfinol unit revealed that a considerable number of the equipment had inconsistent tag names across documents.

\section{Inconsistent naming convention}

In the ICS naming system, ' 1101 ' is used to describe a Sulfinol unit, where the first two digits (i.e. '11') represent the Sulfinol 
Table 3. Number of failure events

\begin{tabular}{|c|c|c|c|c|c|c|c|c|c|}
\hline \multirow{2}{*}{ PLC location } & \multicolumn{8}{|c|}{ Number of failure events in years } & \multirow{2}{*}{ Sum } \\
\hline & 1 & 2 & 3 & 4 & 5 & 6 & 7 & 8 & \\
\hline Control room 1 & 1 & 7 & 3 & 2 & 2 & 5 & 2 & 2 & 24 \\
\hline Control room 2 & 3 & 4 & 4 & 6 & 0 & 4 & 8 & 11 & 40 \\
\hline Control room 3 & 0 & 0 & 0 & 0 & 2 & 3 & 2 & 10 & 17 \\
\hline Control room 4 & 1 & 3 & 4 & 0 & 6 & 11 & 2 & 6 & 33 \\
\hline Control room 5 & 2 & 0 & 1 & 2 & 6 & 6 & 7 & 7 & 31 \\
\hline Control room 6 & 0 & 0 & 0 & 0 & 0 & 1 & 1 & 0 & 2 \\
\hline Control room 7 & 1 & 0 & 0 & 0 & 0 & 1 & 0 & 1 & 3 \\
\hline Control room 8 & 0 & 1 & 1 & 0 & 0 & 1 & 0 & 0 & 3 \\
\hline Control room 9 & 0 & 0 & 0 & 0 & 0 & 3 & 1 & 1 & 5 \\
\hline Control room 10 & 1 & 1 & 0 & 0 & 0 & 2 & 1 & 1 & 6 \\
\hline Control room 11 & 0 & 1 & 3 & 0 & 1 & 3 & 2 & 5 & 15 \\
\hline Control room 12 & 4 & 2 & 1 & 0 & 2 & 8 & 0 & 3 & 20 \\
\hline Sum & 13 & 19 & 17 & 10 & 19 & 48 & 26 & 47 & 199 \\
\hline
\end{tabular}

unit and the last digit (i.e. ' 1 ') indicates that the unit belongs to 'LNG train 1'. Thus, all the instrument tag numbers relating to the Sulfinol nit of LNG train 1 should have a prefix of ' 111 ' indicating the location of the instrument (Figure 3).

A detailed examination of the six P\&IDs revealed that only two had the correct prefix ' 111 '. The other four drawings had been incorrectly labelled with the location prefix '11' (Figure 3). This inconsistent labelling discontinues the link between drawings and therefore makes it extremely difficult for engineers to decipher the information that they require. Discussions with a lead engineer in company EIC confirmed that this inconsistent labelling was an oversight. Instead of rectifying this issue on the P\&IDs, the engineering team decided not to correct them, as a revision and their reissue would have been costly and time-consuming and impacted their schedule and margins.

\section{Errors and incorrect annotation}

Several errors and incorrect annotations on the P\&IDs were identified. In ISA-S5.1 (ISA, 1991), the symbol for a local, fieldmounted instrument is defined as a circle with letters and numbers inside denoting its function and loop. A circle with a single horizontal line inside represents a device that is located in the main control panel. It was revealed, however, that a total of 55 local field-mounted instruments on the P\&IDs had been incorrectly annotated as a device residing in a central control panel.

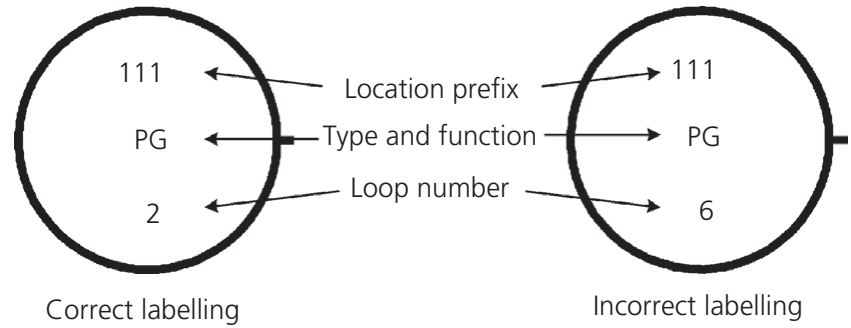

Figure 3. Inconsistent labelling of instrument symbols
Figure 4 denotes a portion of a P\&ID that describes the knockout-drum (KOD) process for treated gas. The function of the KOD is to remove the Sulfinol solvent residual, by washing the treated gas with water. To monitor and control the water level in the KOD, a local-level transmitter should be installed in the vessel so that it can deliver a level signal to a remote controller. The controller will then generate, based on the set point and predefined logic, an output command to regulate the opening of a control valve to ensure that an appropriate water level is maintained. As shown on the left of Figure 4, the as-built process loop was incorrectly documented. Here the local level transmitter was omitted, and a remote controller, which should have been placed in the main control panel, was displayed instead. On the right-hand side of Figure 4, a corrected version is presented.

A significant number of field control valves were also incorrectly labelled on the P\&IDs. For example, in Figure 4, a level control

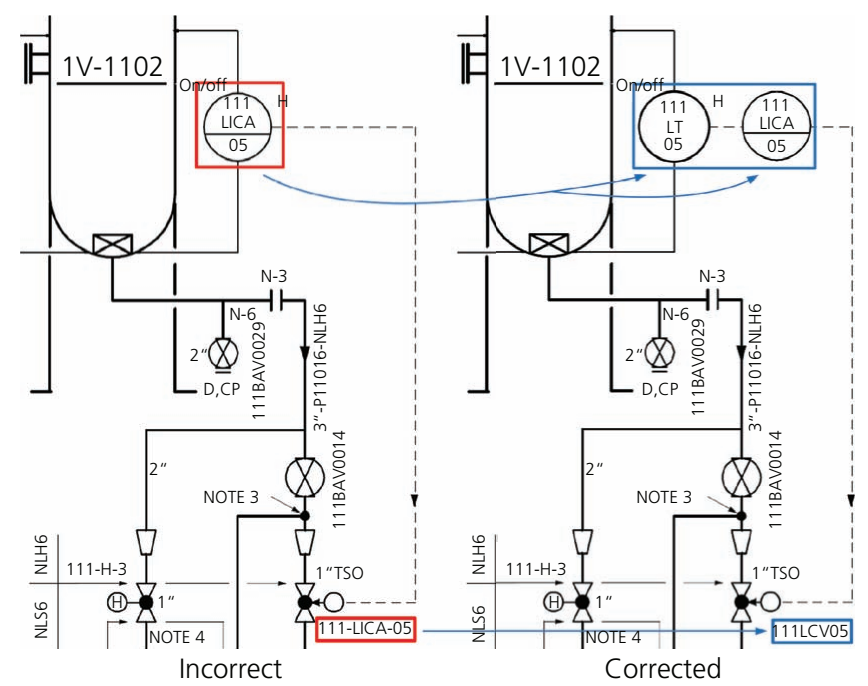

Figure 4. Incorrect notation and inconsistent labelling 


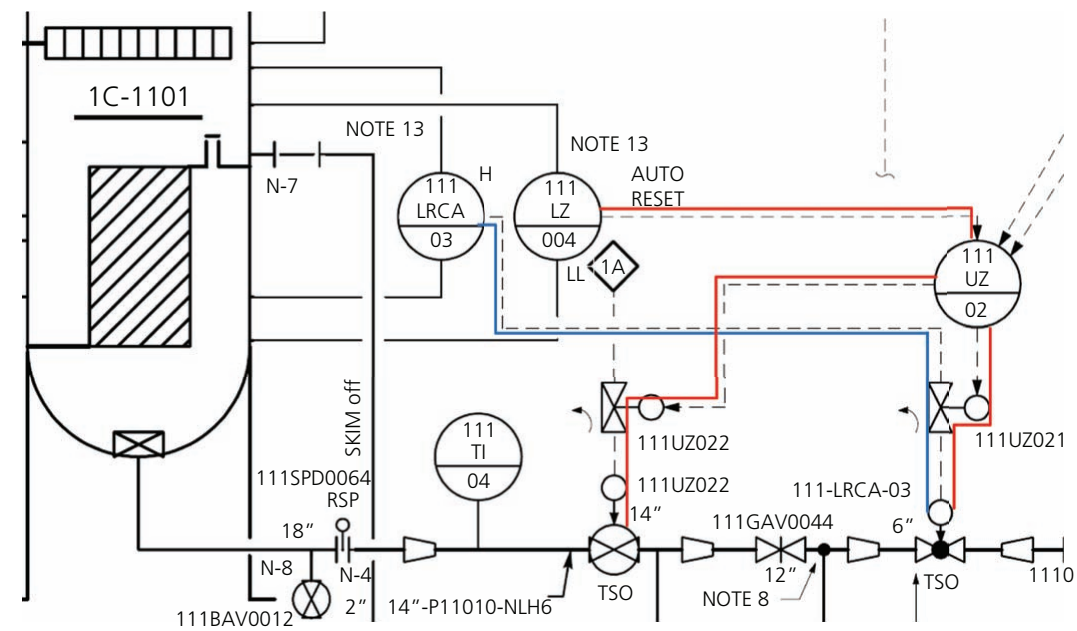

Figure 5. Absorption vessel solvent level control

valve was incorrectly labelled as 111-LICA-05. However, it was found to have been labelled as 111LCV05 on a process loop diagram.

\section{Acid-absorption process: non-conformances}

Figure 5 presents a portion of a P\&ID that illustrates the absorption process for acid gas. The lower part of the absorption vessel, where the fat solvent accumulates, is shown on the lefthand side of Figure 5.

A discharging pipe is connected to the bottom of the vessel to regulate the fat solvent's level. For most oil and gas installations, there are three types of control strategies adopted: $(a)$ process control, $(b)$ protective control and (c) fire and gas system. The relationship between these control strategies can be viewed in Figure 6. Typically, an LNG plant operates within a region determined by the control system. Abnormal events may drive plant conditions beyond their safe operating limits. If this situation

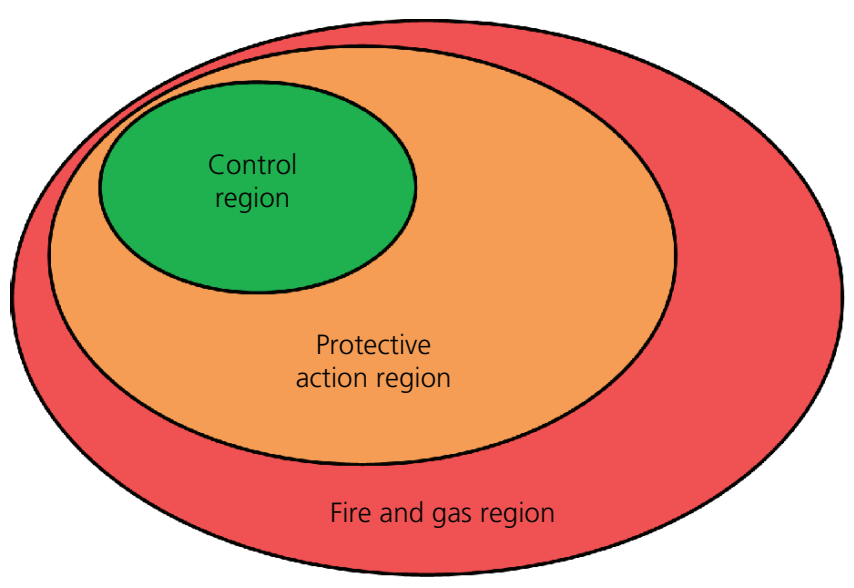

Figure 6. Relationship between control and protective systems arises, the system escalates to protective action and shuts down equipment, or the entire plant, to prevent damage, hazards to personnel and the discharge of process fluids into the atmosphere.

In circumstances where the protective systems fail to detect the process deviation or there is an event that is not measured by the control and protective systems that results in a fire or gas leak, the system triggers an alarm and shuts down the affected equipment or plant to minimise the risk of an explosion. For the system presented in Figure 5, two types of control strategies are adopted.

n Process. The detector monitors the fat solvent level in vessel 1C-1101. Based on the measured signals, control commands are generated and sent to actuate the solenoid valve 11UZ021, which then operates the control valve 111-LRCA-03 to regulate the solvent level in $1 \mathrm{C}-1101$.

- Protective. To prevent the natural gas from entering the discharge pipe and reaching the downstream flashing tank, a minimum solvent level must be maintained in the absorber 1C-1101. To achieve this, a protective loop is designed that is independent of the process control loop. A level detector is used to monitor the level of the fat solvent. When the level reaches the lower limit, a control command will be generated by 111-UZ-02 which, by overriding the command of the process control loop, will operate the two solenoid valves (11UZ021 and 111UZ022) to close the corresponding control valves (111-LRCA-03 and 111UZ022) and stop the solvent from being discharged from the vessel.

An examination of the documents revealed a number of design non-conformances (Figures 4 and 5). The field instruments were incorrectly annotated as control components that should have resided in the remote panels. Table 4 lists the inconsistent tagging identified for the two control loops presented in Figure 5. The P\&ID instruments, for example, are tagged as IC-1101 and on the C\&E as 1C1101 (Table 4). 
Table 4. Example of inconsistent labelling of instrument tags

\begin{tabular}{|c|c|c|c|c|c|c|}
\hline \multicolumn{6}{|c|}{ Instrument tagging } & \multirow{3}{*}{$\begin{array}{c}\text { Number of } \\
\text { different } \\
\text { types }\end{array}$} \\
\hline \multirow{2}{*}{ P\&ID } & \multirow{2}{*}{ Loop diagram } & \multirow{2}{*}{ C\&E } & \multirow{2}{*}{ Alarm } & \multicolumn{2}{|c|}{ Software } & \\
\hline & & & & Process & Safety & \\
\hline 1C-1101 & N/A & 1C1101 & 1C1101, C1101 & N/A & $\mathrm{N} / \mathrm{A}$ & 3 \\
\hline 111LRCA03 & 111LT03 & N/A & 111LC003 & 111LT03, 111LC003 & N/A & 4 \\
\hline 111LZ004 & 111LZ004 & 111LZA004, 111LZ004 & 111LT004, 111L004 & N/A & 111LZTO04 & 5 \\
\hline $111 \mathrm{UZO2}$ & N/A & N/A & 111 UZO2 & N/A & 111 UZO2 & 1 \\
\hline 11UZ021 & 111 UZ021 & 111UZO2-1, 111 UZO21 & N/A & 111 UZ021 & U111UZ021 & 4 \\
\hline 111-LRCA-03 & 111LCV03 & 111LRCA03 & $\mathrm{N} / \mathrm{A}$ & 111LV03 & U111UZ021 & 5 \\
\hline 111UZ022 & 111 UZO22 & 111UZO2-2, 111 UZO22 & N/A & 111 UZO22 & U111UZ022 & 3 \\
\hline 111UZO22 & N/A & U111UZ022 & N/A & 111UCV022 & U111UZ022 & 3 \\
\hline
\end{tabular}

N/A, not available

It was also found that some equipment, which is presented in the control loops in Figure 5, had been each assigned with multiple tag numbers. For example, a level transmitter and control valve each have been assigned five different tags. These tags are spread over a number of different documents, therefore making it difficult to determine the relationships between them.

\section{Digital engineering with a system information model}

The concept of "SIM is a derivative of BIM, with "building" being replaced with "system" to represent the process of modelling complex connected systems' (Love et al., 2016b: p. 156). Connected systems are unable to be described in a threedimensional model, as they do not possess geometrical properties. The objects modelled in an SIM environment have a 1:1 relationship with the objects in the physical system. Components, connections and functions are defined and linked as they would be in the real world. As a result, SIM is able to create a digital twin for connected systems.

An SIM is created using a relational database system that can be accessed through software such as Digital Asset Delivery (DAD). As a SIM is object oriented and hierarchical, its 'children' inherit attributes and data from their 'parents' (Zhou et al., 2015). The adoption of an object-oriented approach can significantly reduce the amount of time needed to enter data into the system to achieve the goal of 'input once, use forever' (Zhou et al., 2015). Each object created in a SIM forms a single source of truth of its real-world counterpart with all the related information attached to that object.

\section{SIM-based ICS design}

The engineering design of ICS can be performed directly in a digital environment enabled by SIM. Different engineering teams can simultaneously collaborate on a project by working on the same SIM database. The object models created in a SIM are dynamically interconnected and can be shared across different engineering teams and controlled through various authorisation levels. Two basic types of relationships are established within a SIM with respect to the objects that are created: $(a)$ inner and $(b)$ inter (Figure 7). An inner relationship describes the connections between components within a layer, such as cables and signals that are modelled as connectors. An interrelationship is used to join the information from different disciplines between layers, such as electrical, ICS and communications.

According to Zhou et al. (2015), a SIM should be introduced during a project's conceptual phase in conjunction with a format that will enable the capture and recording of important project data at the point of origin, including equipment lists, product data sheets, warranties, spare parts lists and preventive maintenance schedules. The capturing of such information is essential to support operations, maintenance and asset management once an LNG plant is in service. Within the building industry, for example, the Construction Operations Building Information Exchange (Cobie) is an international standard that is used to capture and record information throughout a project's various phases (East, 2007). The Cobie standard can be potentially modified and utilised by the LNG sector.

In this case study, the fat-solvent-level control loops, which are shown in Figure 5, are used as an example to illustrate how a digital model can be created to represent the connections and functions of the physical system. In this research, it has been assumed that a component may have various tag numbers, as this has been identified to arrive in practice in the engineering of LNG plants (Love et al., 2017). It is worth noting that only the

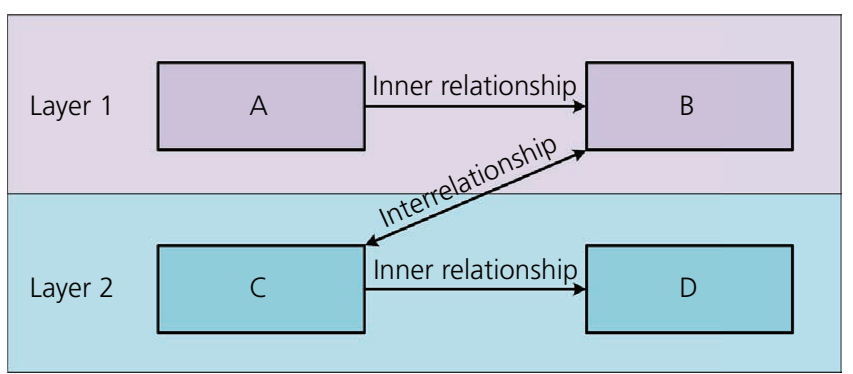

Figure 7. SIM object relationships 


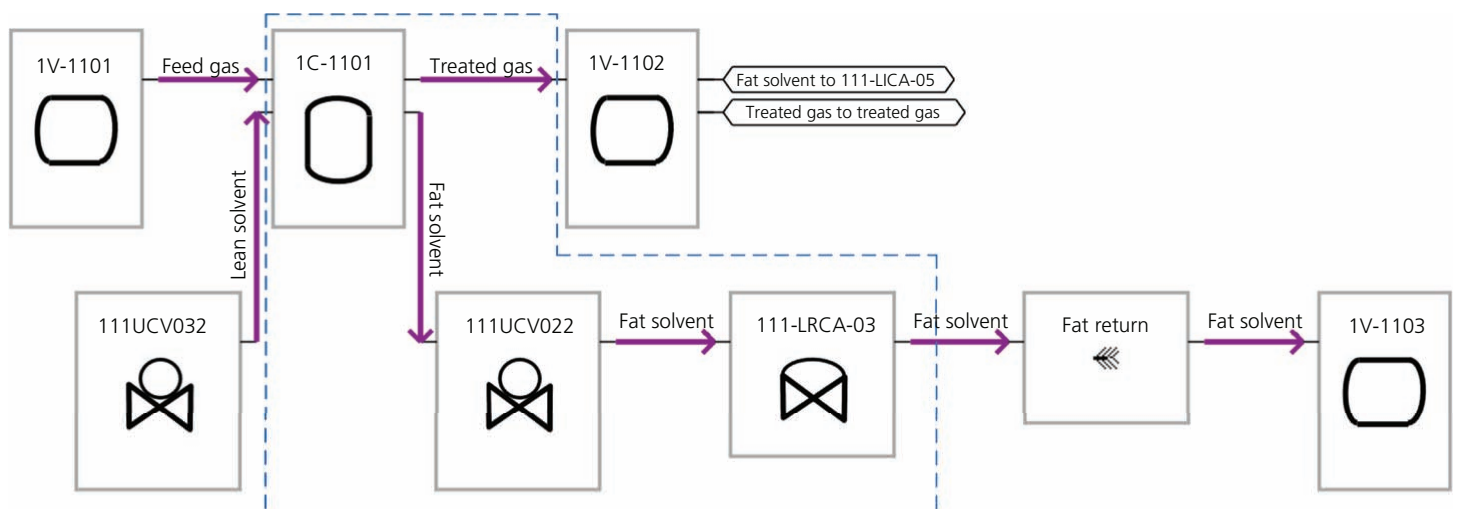

Figure 8. Process-flow design example

equipment that is electrically interconnected is considered. Piping and mechanical designs have been excluded.

\section{Process-flow design}

A dedicated 'process layer' is created in the SIM for engineers to design various process flows. Vessels, valves and devices that are directly involved in material processing can be modelled in this layer. Figure 8 illustrates the structure of the absorption process. The acid gas exits the KOD $1 \mathrm{~V}-1101$ and reaches the absorber $1 \mathrm{C}-1101$, where it interacts with the lean solvent to remove the acid compositions. The treated gas is then sent to KOD 1V-1102, and the fat solvent is delivered to the flashing tank through two control valves $111 \mathrm{UCV} 022$ and 111-LRCA-03. The fat solvent level control section that is highlighted by the dashed-line box is used as an example for modelling in an SIM environment.

Components modelled in a SIM are classified based on their 'location' and 'type'. The location shows the physical position of the component within a plant, and the type indicates its functionality. This classification complies with the common practices that have been adopted by many object-oriented software applications. Connections between components, such as cables, signals and piping, can be modelled as connectors that are classified into types. Additional attributes can be defined and assigned to objects to facilitate the design.

Attributes can also be defined and assigned to a parent folder. Therefore, all the children under the folder can inherit the attribute from their parent (Figure 9). This method significantly decreases the time to enter data and therefore potentially reduces the number of design errors and omissions, as information is inputted only once. Figure 10 displays a portion of the information created for the absorber 1C-1101.

In Figure 8, two control valves (111UCV022 and 111-LRCA-03) are used to regulate the level of the fat solvent in 1C-1101. Each of these two control valves is actuated by a solenoid valve that is attached. By energising or de-energising the solenoid valve using

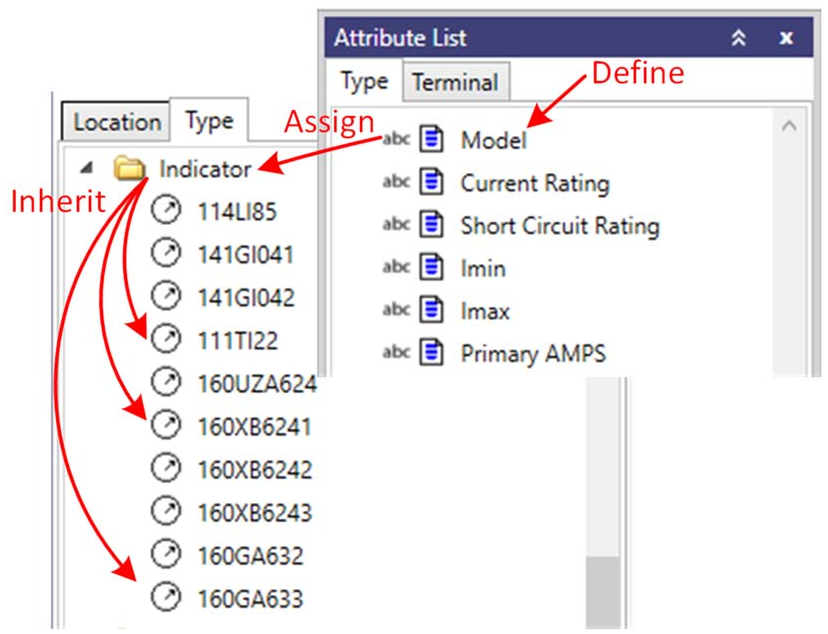

Figure 9. Attribute assignment

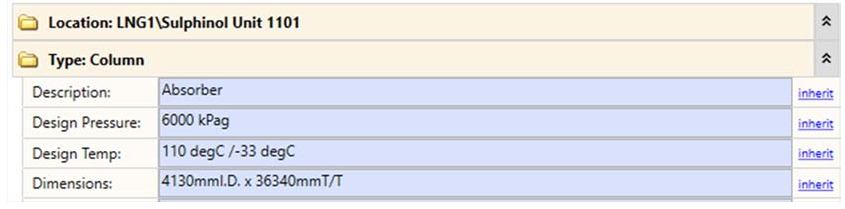

Figure 10. Information for absorber 1C-1101

a control command, the corresponding control valve can open or close the discharging pipe to maintain the solvent's level, which is wired to the controllers.

\section{Process and protective control design}

A process control and protective control loop are designed to enhance safety performance and avoid a single point of failure. The two control loops are usually designed independently of each other. There is a tendency for different tagging and naming conventions to be introduced. As previously mentioned, this 


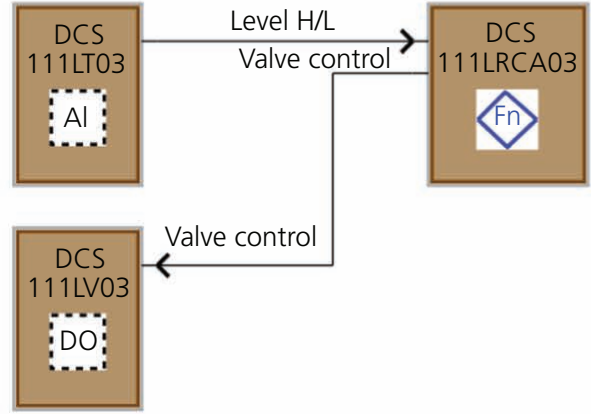

(a)

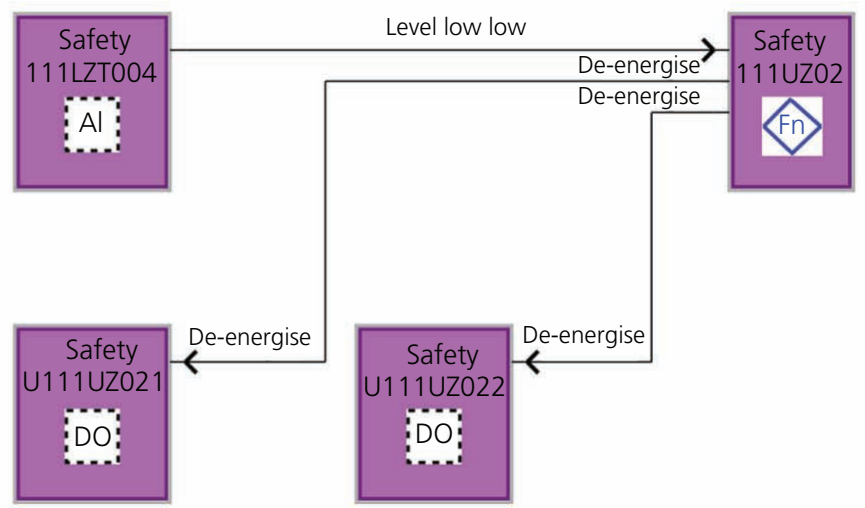

(b)

Figure 11. Process and protective control: (a) DCS control function; (b) safety control function

situation can arise due to organisations adopting their own standards and due to software coding requiring a certain length for tag numbers to be specified.

In addressing this problem, two functional layers are created for the design of the process (i.e. distributed control system (DCS)) and protective control (i.e. safety) systems. In the DCS, the level transmitter 111LT03 detects and transmits a signal to a control device which, in this instance, is a local process control PLC. The PLC will then generate a control command to adjust the opening of a valve to regulate the solvent level. This function can be modelled in the DCS layer as can be seen in Figure 11(a). Instruments and functions can also be modelled as components. The signal flows can be created as directed connectors indicating the information transmission between components. The protective control functions can be modelled in the 'safety' layer in a similar manner (Figure 11(b)).

The alarm can be defined as an attribute and assigned to the components in the corresponding layers (Figure 12).

\section{Instrumentation system design}

A 'base' layer is created to model the connected system of the physical equipment and cables. The function of the base layer can be extended beyond the loop diagram. It shows not only the block diagram, but also the terminations. Project data can be attached to the relevant components and connectors using attributes. Moreover, reference documents such as data sheets, photographs and notes can be uploaded into the SIM model and linked to the corresponding objects. Forms such as requests for information and

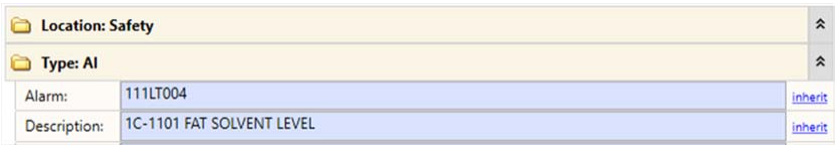

Figure 12. Alarm setting through attribute inspection test reports can also be defined in the SIM and assigned to objects. Figure 13 illustrates the components and connections of the instrumentation system in the base layer. Signals are transmitted between the instruments, controllers, and actuators through a number of cables and junction boxes.

The electrical power supply to the ICS can also be designed in the SIM. As noted earlier, the electrical design data were not made available. With this in mind, a conceptual design is created to demonstrate a simplified power supply system. Figure 14 shows the electrical power supply route from a switchboard of a substation to the local PLC rack panels.

\section{Linking information}

In this research, four layers have been used to design the ICS. The SIM model was constructed based on the inputs from several specific engineering disciplines. Different tagging and naming conventions have been introduced into the system. This results in multi-tag numbers being allocated to a single object across different layers. For example, a control valve is named 111LRCA-03 in the process layer. Its tag numbers in the DCS, safety and base layers are 111LV03, U111UZ021 and 111LCV03, respectively. Thus, one component has a different name in each of the four layers, which increases the complexity of the system and reduces information traceability. This issue can be addressed using a 'relationship' function provided in the SIM that enables interconnections to be linked between objects from different layers.

Figure 15 shows the interconnected tag numbers of the control valve in different layers. Using this method, an object's information can be linked together between layers, forming a dynamic link. The interlayer linking system forms an effective and efficient tool for trace information. Additionally, it can also be used as a powerful tool for inspecting the integrity of the design. For example, a control valve is found in the process layer and its function is found in the DCS layer. However, if a 


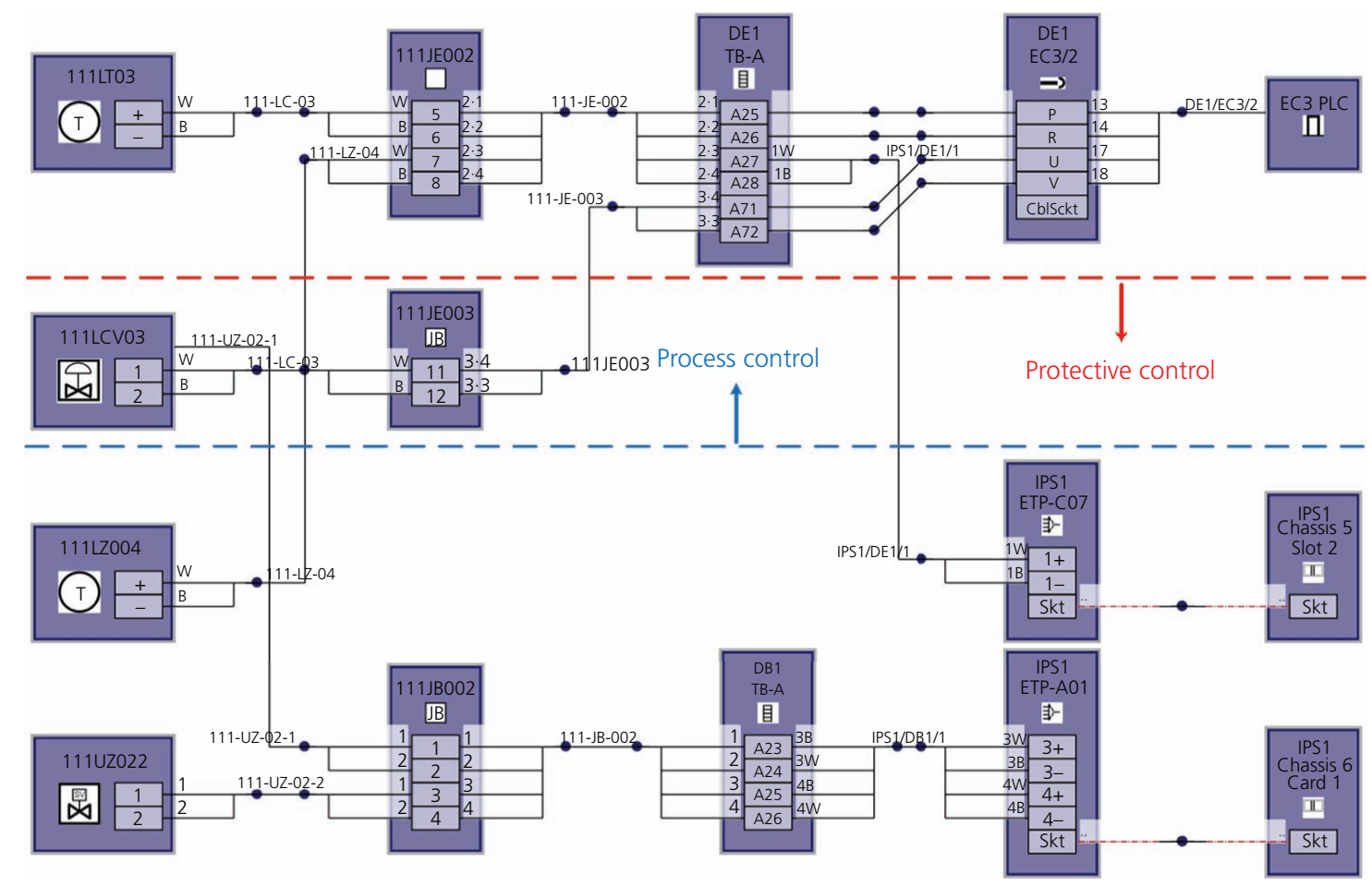

Figure 13. Process and protective control loops

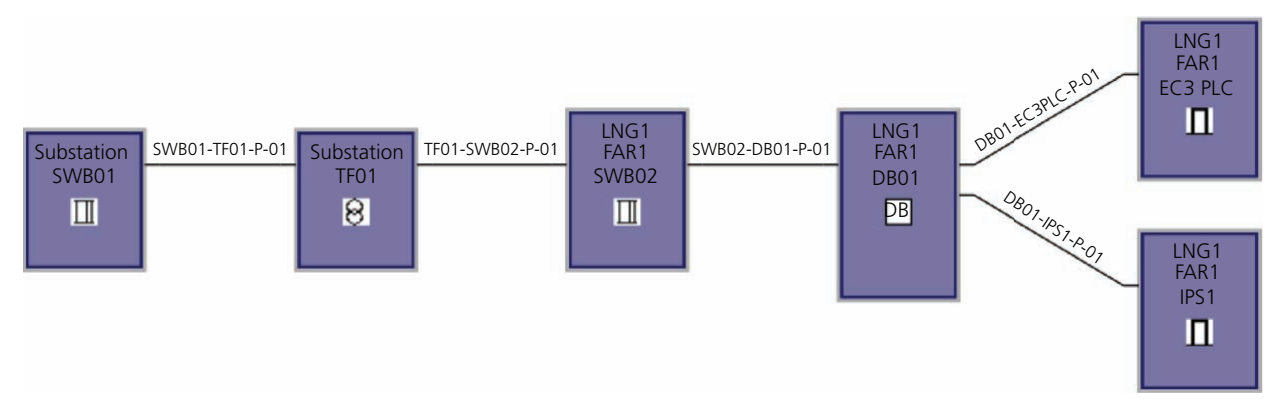

Figure 14. Concept power supply design

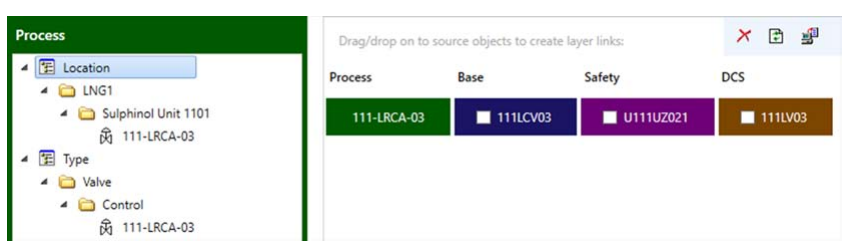

Figure 15. Interconnection between layers

corresponding component for the physical valve cannot be identified in the base layer, there is likely to be a design omission.

The use of the SIM layer concept can enable multiple engineering functions to work simultaneously on the same database. This form of collaboration cannot be undertaken in the traditional Cad environment used to design LNG plants. The embedded objectoriented functioning of a SIM enables engineering design to create a digital model that can dynamically link project-related data that can be readily traced, interpreted and verified.

\section{Ex ante evaluation of SIM}

The use of object-oriented software approaches has become an integral part of engineering design, but, in the case of ICSs, this is an area that has received limited attention. Attention has typically focused on modelling those elements that possess geometry, as they are tangible artefacts that tend to be visible. Yet ICSs do not possess geometry, and, therefore, information needs to be modelled. SIM focuses on structuring information in a way that enables engineers and its users, particularly those in operations 
and maintenance, to access instantly the required data within a digital environment. There is no longer a need to produce paperbased engineering documents at any stage of an LNG plant's life cycle; errors, omissions and information redundancy can be significantly reduced. Additionally, a significant cost saving can be obtained as the physical storage of as-built documentation is no longer required, as they can be kept digitally in a standardised format and in a single location. There will be, however, a need to update the data format periodically to avoid digital obsolescence.

Analysis of the Cad-based documents of the Sulfinol unit of the LNG plant enabled errors, omissions and information redundancy to be identified. A digital SIM was then retrospectively constructed. Due to issues of commercial confidentiality, access to the time and costs to develop the documentation for the Sulfinol unit could not be provided. As noted earlier, previous empirical research that examined the time to produce ICS drawings from SIM revealed that this task takes approximately 2 hours rather than the 40 person-hours needed when using Cad (Love et al., 2013). The adoption of SIM eliminates the role of the draughtsperson and the need for engineers to spend time checking and approving drawings (Sheedy, 2016).

In the case of implementing and commissioning of a gas metering upgrade project, Love et al. (2017) estimated a 95\% cost reduction to produce ICS documentation if SIM had been employed instead of Cad. This estimation compares with the $94 \%$ cost saving and productivity improvement in the ICS documentation process that was previously demonstrated by Love et al. (2013). Considering the experiences from the case presented and previous studies, an ex ante evaluation for the cost, benefits and risks of SIM are identified in Table 5.

The costs and benefits of using SIM are explicit, but there are a number of risks that also need to be considered beyond digital obsolescence (Simpson and Harris, 2017). In particular, LNG operators will need to consider and put in place a plan to ensure the interoperability of their existing systems with SIM. An information framework needs to be established and managed to ensure that their different software applications are able to exchange data with a SIM via a common set of exchange formats, to read and write the same file formats and to use the same protocols. In the case of any organisation adopting software solution, issues associated with proprietary obsolescence and data accessibility also come to the fore (Simpson and Harris, 2017).

The adoption of SIM provides a new way to engineer and manage digitally an LNG plant's asset information for ICSs. Naturally, technological innovations such as SIM that is incongruous with established work practices will be confronted with strong scepticism and a lack of legitimacy. How such legitimacy is created and enacted by LNG operators will not automatically result from championing the use of SIM, but also empirically identifying the failure and bottlenecks of using software systems that are not object oriented in nature.

To this end, future research should focus on establishing governance structures and processes that can be used to measure (e.g. qualitatively and quantitatively) and manage the expected benefits of SIM. The deployment of digital technologies, such as SIM, is a relatively straightforward process, but understanding 'how' they can be used remains a challenge. Understanding the business context and the problem that SIM will address is fundamental for ensuring that benefits can materialise. Equally, LNG operators that decide to implement SIM will need to initiate a change management process; after all, benefits will unable to be realised unless change is undertaken. Highlighting the symbiotic relationship that exists with benefits and change, Peppard (2016) cogently states 'benefits are unable to delivered without change, and change without benefits cannot be sustained'. Thus, future research will need to focus on identifying the enablers of change that will deliver the expected benefits of SIM.

Table 5. Ex ante evaluation of SIM

\begin{tabular}{|c|c|c|c|c|}
\hline Construct & Criteria & High & Medium & Low \\
\hline \multirow[t]{5}{*}{ Cost } & Software and upgrades (e.g. DAD) & & $\checkmark$ & \\
\hline & Training & & $\checkmark$ & \\
\hline & Production of documentation/digital model & & & $\checkmark$ \\
\hline & Life-cycle management of asset data & & & $\checkmark$ \\
\hline & Labour (e.g. no longer a requirement for a draughtsperson) & & & $\checkmark$ \\
\hline \multirow[t]{5}{*}{ Benefit } & Productivity & $\checkmark$ & & \\
\hline & Information redundancy & & & $\checkmark$ \\
\hline & Usability and manageability & $\checkmark$ & & \\
\hline & Teamwork features (e.g. collaboration) & $\checkmark$ & & \\
\hline & Consolidated point of truth & $\checkmark$ & & \\
\hline \multirow[t]{6}{*}{ Risk } & Digital obsolescence & $\checkmark$ & & \\
\hline & Interoperability & $\checkmark$ & & \\
\hline & Contractual issues (e.g. requirement to use SIM) & & $\checkmark$ & \\
\hline & Propriety obsolescence & $\checkmark$ & & \\
\hline & Data accessibility (e.g. reliance on the cloud) & $\checkmark$ & & \\
\hline & Change management (e.g. new processes and practices associated with SIM adoption) & & $\checkmark$ & \\
\hline
\end{tabular}




\section{Conclusion}

ICSs play a critical role in ensuring the operation, production and safety of an LNG plant. Having instant access to accurate and reliable information during a plant's operation and maintenance enables the plant to run efficiently with minimum shutdown times and therefore can ensure the effective supply of gas to domestic and international markets.

While the energy sector has embraced object-oriented software applications to engineer and document projects across a number of disciplines, such as the civil, structural, mechanical and hydraulic fields, they have still relied on Cad tools and enabled processes for ICSs. This has adversely impacted the quality of as-built documentation that is produced and presented to operators at the handover of an LNG plant's construction. Invariably, such documentation contains errors, omissions and possesses considerable information redundancy, rendering the task of information retrieval during operations and maintenance to be a toilsome and taxing process. This can adversely impact productivity, particularly during shutdown periods, and result in a reduction of LNG supply.

To future-proof an LNG plant's ICS, it has been put forward in this paper that SIM should be adopted during the formative stages of the design process, enabling it to be utilised effectively throughout its life cycle. A case study is used to highlight examples of problems that emerge when an object-oriented approach, such as SIM, is not implemented. The benefits of switching from Cadbased ICS documentation to a digital engineering environment enabled by SIM are ten-fold and will enable the LNG sector to ameliorate the performance of their plants.

\section{REFERENCES}

Appea (Australian Petroleum Production and Exploration

Association) (2017) Key Statistics for 2017. Appea, Canberra,

Australia. See https://www.appea.com.au/wp-content/uploads/2017/05/

APPEA_Key-Stats-2017_web_revised.pdf (accessed 31/12/2017).

BCA (Business Council of Australia) (2013) Securing Investment in Australia's Future: Report of the Project Costs Task Force. BCA, Melbourne, Australia. See https://d3n8a8pro7vhmx.cloudfront.net/bca/ pages/3495/attachments/original/1530782962/Securing_Invmt_in _Australias_Future_Project_Costs_FINAL_8.8.2013.pdf?1530782962 (accessed 31/12/2017).

Chambers M (2010) Woodside Petroleum puts \$12bn Pluto gas project cost on review. The Weekend Australian, 23 October. See http://www. theaustralian.com.au/business/woodside-puts-pluto-on-review/newsstory/6cdda937736e31aa5f43d803b04f6b0f (accessed 31/12/2017).

Davis K (2012) Making connections: how new AVEVA technology is transforming productivity in electrical engineering and design. Aveva World Magazine issue 2: 36-38. See http://view.digipage.net/? id=aveva_world_magazine_2012_issue2\&page $=38$ (accessed 28/01/ 2018).

DISR (2017) Gas Resources and Energy Quarterly. Office of the Chief Economist Department of Industry, Science and Resources, Canberra, Australia. See https:/www.industry.gov.au/Office-of-the-ChiefEconomist/Publications/ResourcesandEnergyQuarterlyJune2017/ documents/Resources-and-Energy-Quarterly-June-2017-Gas.pdf (accessed 31/12/2017)

East EW (2007) Construction Operations Building Information Exchange (COBIE): Requirements Definition and Pilot Implementation Standard.
Construction Engineering Research Laboratory, US Army Engineer Engineering Development Research Centre, Champaign, IL, USA, ERDC/CERL TR-07-30. See https://ntrl.ntis.gov/NTRL/dashboard/ searchResults/titleDetail/ADA491932.xhtml\# (accessed 06/01/2018).

Fakhimi A, Sardrood JM, Marzroi A, Ghoreishi SR and Azhar S (2017) Influences of building information modelling on oil, gas, and petrochemical firms. Science and Technology for the Built Environment 23(6): 1063-1077, https://doi.org/10.1080/23744731.2017.1338487.

Gerring J (2005) Case study research. In Case Study Research: Principles and Practices. Cambridge University Press, New York, NY, USA, pp. xi-xii.

IEC (International Electrotechnical Commission) (2008) IEC 613551:2008: Classification and designation of documents for plants, systems and equipment - part 1: Rules and classification tables. IEC, Geneva, Switzerland.

ISA (International Society of Automation) (1991) ISA-5.4-1991: Instrument loop diagrams. ISA, Durham, NC, USA.

ISO (International Organization for Standardization) (2005) ISO 146171:2005: Graphical symbols for diagrams - part 1: general information and indexes. ISO, Geneva, Switzerland. See https://www.iso.org/ standard/41838.html (accessed 10/07/2019).

ISO (2012) ISO 10628-2:2012(en): Diagrams for the chemical and petrochemical industry - part 2: graphical symbols. ISO, Geneva, Switzerland. See https://www.iso.org/obp/ui/\#iso:std:iso:10628:-2:ed-1: v1:en (accessed 01/01/2017).

Love PED, Zhou J, Sing CP and Kim JT (2013) Documentation errors in instrumentation and electrical systems: toward productivity improvement using system information modelling. Automation in Construction 35: 448-459, https://doi.org/10.1016/j.autcon.2013.05.028.

Love PED, Zhou J and Kim JT (2014) Assessing the impact of requests for information in electrical and instrumentation engineering contracts. Journal of Engineering Design 25(4-6): 177-193, https://doi.org/10. 1080/09544828.2014.935305.

Love PED, Zhou J and Matthews J (2016a) Systems information modelling: from file exchanges to model sharing for electrical instrumentation and control systems. Automation in Construction 67: 48-59, https://doi.org/10.1016/j.autcon.2016.02.010.

Love PED, Zhou J, Matthews J and Luo H (2016b) System information modelling: enabling digital asset management. Advances in Engineering Software 102: 155-165, https://doi.org/10.1016/j. advengsoft.2016.10.007.

Love PED, Zhou J and Matthews J (2017) Safeguarding asset integrity with digitization: implementation and commissioning of a gas metering upgrade. Journal of Natural Gas Science and Engineering 44: 9-21, https://doi.org/10.1016/j.jngse.2017.04.008.

Love PED, Zhou J and Matthews J (2019) Project controls for electrical instrumentation and control systems: enabling role of digital system information modelling. Automation in Construction 103: 202-212, https://doi.org/10.1016/j.autcon.2019.03.010.

Meier FA and Meier CA (2011) Instrumentation and Control Systems Documentation, 2nd edn. ISA Durham, NC, USA. See https://www. isa.org (accessed 18/08/2018).

Mejilænder-Larsen Ø (2015) Generalising via the case studies and adapting the oil and gas industry's project execution to concepts to the construction industry. Procedia Economics and Finance 21: 271-278, https://doi.org/10.1016/s2212-5671(15)00177-x.

Moloney M, McKenna T, Fitzgibbon K and McKeogh E (2017) Quality data for strategic infrastructure decisions in Ireland. Infrastructure Asset Management 4(2): 40-49, https://doi.org/10.1680/jinam.16.00011.

Olaniran OJ, Love PED, Edwards DJ, Olatunji O and Matthews J (2015) Cost overruns in hydrocarbon mega-projects: a critical review and implications for research. Project Management Journal 46(6): 126-138, https://doi.org/10.1002/pmj.21556.

Olaniran OJ, Love PED, Edwards DJ, Olatunji O and Matthews J (2017) Explaining cost overruns in hydrocarbon megaprojects: the application 
of chaos theory. Journal of Construction Engineering and Management 143(2), https://doi.org/10.1061/(ASCE)CO.1943-7862.0001227.

Parnell L (2013) Instrumentation, control systems contribute to sustainability. Ethanol Producer Magazine, June: pp. 80-84. See http://www.ethanolproducer.com/articles/9845/instrumentation-controlsystems-contribute-to-sustainability (accessed 20/08/2018).

Peppard J (2016) What about the benefits? A missing perspective in software engineering. Proceedings of the 10th International Symposium on Empirical Software Engineering and Measurement, Ciudad Real, Spain. See http://alarcos.esi.uclm.es/eseiw2016/ downloads/keynote_peppard_esem2016.pdf (accessed 01/04/2018).

Pocock D, Shetty N, Hayes A and Watts J (2014) Leveraging the relationship between BIM and asset management? Infrastructure Asset Management 1(1): 5-7, https://doi.org/10.1680/iasma.13.00013.

Sheedy C (2016) Mining goes paperless. Engineers Australia, March: 58-63. See https://www.dad.net.au/2016/04/12/mining-goes-paperless/ (accessed 18/08/2018).
Simpson D and Harris N (2017) Briefing: An integrated approach to asset management system IT selection and implementation. Infrastructure Asset Management 4(3): 83-86, https://doi.org/10.1680/jinam.16. 00019 .

Smyth J (2017) Inpex’s \$37bn Australia LNG project hit by dispute. Financial Times, 15 March. See https://www.ft.com/content/81b47a4e0928-11e7-97d1-5e720a26771b (accessed 31/12/2017).

Stacks DW (2013) Case study. Encyclopaedia of Public Relations (Heath RL (ed.)). Sage, Los Angeles, CA, USA, https://doi.org/10. 4135/9781452276236.

Yin RK (2014) Case Study Research: Design and Methods, 5th edn. Sage Van Nuys, CA, USA.

Zhou J, Love PED, Matthews J, Carey B and Sing CP (2015) An objectoriented model for life cycle management of electrical instrumentation control projects. Automation in Construction 49: 142-151, https://doi. org/10.1016/j.autcon.2014.10.008.

\section{How can you contribute?}

To discuss this paper, please submit up to 500 words to the editor at journals@ice.org.uk. Your contribution will be forwarded to the author(s) for a reply and, if considered appropriate by the editorial board, it will be published as a discussion in a future issue of the journal. 